\title{
Who sells tobacco, who stops? A comparison across different tobacco retailing schemes
}

\author{
Suzan Burton (D) , ${ }^{1}$ Fiona Phillips, ${ }^{2}$ Christina Watts, ${ }^{3,4}$ Kelly Kennington, ${ }^{2}$ \\ Michelle Scollo, ${ }^{5}$ Kylie Lindorff, ${ }^{6}$ Sam Egger $^{7}$
}

\begin{abstract}
- Additional material is published online only. To view please visit the journal online (http://dx.doi.org/10.1136/ tobaccocontrol-2019-055561).

${ }^{1}$ School of Business, Western Sydney University, Sydney, New South Wales, Australia ${ }^{2}$ Cancer Prevention and Research Division, Cancer Council Western Australia, Perth, Western Australia, Australia ${ }^{3}$ Cancer Prevention and Advocacy Division, Cancer Council New South Wales, Sydney, New South Wales, Australia

${ }^{4}$ Sydney School of Public Health, The University of Sydney, Sydney, New South Wales, Australia

${ }^{5}$ Cancer Council Victoria, Melbourne, Victoria, Australia ${ }^{6}$ Ouit Victoria, Cancer Council Victoria, Melbourne, Victoria, Australia

${ }^{7}$ Cancer Research Division, Cancer Council New South Wales, Sydney, New South Wales, Australia
\end{abstract}

\section{Correspondence to}

Professor Suzan Burton, Western Sydney University School of Business, Sydney, NSW 2747, Australia;

S.Burton@westernsydney. edu.au

Received 11 December 2019 Revised 30 April 2020 Accepted 1 May 2020 Published Online First 2 July 2020

\section{Check for updates}

(C) Author(s) (or their employer(s)) 2021. No commercial re-use. See rights and permissions. Published by BMJ.

To cite: Burton S, Phillips $F$ Watts C, et al. Tob Control 2021:30:392-398.

\section{ABSTRACT}

Background Licensing of tobacco retailers has been proposed as a mechanism to encourage retailers to stop selling tobacco. However, previous studies of tobacco licensing and/or of retailers who have stopped selling have been restricted to one legislative environment. This study examines patterns of tobacco retailing across three legislative environments with three different licensing schemes (an annual fee-based licence, a zero-cost, one-off notification scheme and no notification/licensing scheme).

Method A telephone survey was conducted of 2928 potential tobacco retailers who could personally choose whether or not to sell tobacco (rather than the decision being made at a head office).

Results Unexpectedly, the annual licence fee to sell tobacco was not significantly associated with a lower rate of selling tobacco or a higher rate of stopping. After allowing for other factors, probability of selling, stopping selling and reported importance of tobacco sales varied across outlet types $(p<0.001$ for all three outcomes), and according to the remoteness of the retailer $(p<0.001, p$ trend $=0.041$ and $p=0.025$ respectively).

Conclusion A fee of $\$ A 286$ was not associated with a lower rate of selling, or a higher rate of stopping. The effect of licensing on retailer numbers will presumably be greater for higher licence fees, but will also depend on the perceived importance of tobacco sales to the retailer. In turn, importance of tobacco sales appears to depend on market factors, including proximity to major urban centres and low-cost competitors. A higher licence fee is likely to have a larger effect on discouraging retailers from selling.

\section{INTRODUCTION}

Permitting 'widespread sales of the single most deadly consumer product in history' has recently been summed up as 'a public health failure that must be addressed'. ${ }^{1}$ Although the quote is recent, the ongoing health problems caused by tobacco have resulted in discussion of a tobacco 'endgame' since $2010 .^{2}{ }^{3}$ There is no consensus, however, on whether new policies are needed to achieve variously defined endgame goals. ${ }^{14}$ However, many authors have suggested that licensing of tobacco retailers and/or zoning restrictions for tobacco sales provide a variety of mechanisms for reducing tobacco consumption, and thus moving towards an endgame for tobacco. ${ }^{5-7}$ A licence to sell tobacco with an annual fee appears to result in some retailers stopping selling, ${ }^{8}$ particularly if there is a sharp increase in the annual fee. ${ }^{9}$
A licensing system also enables density-based and/or proximity-based caps on new tobacco retailing licences, preventing new licences being issued based on proximity to other retailers or near schools, and thus (presumably) leading to a reduction in the number of retailers when existing stores decide to give up their permit. ${ }^{10}$ Licensing also provides a mechanism for enforcement of tobacco control regulation, ${ }^{7}$ something that is particularly important since retailers who do not comply with licensing regulations are more likely to violate regulations on tobacco display and sales. ${ }^{11}$

A licence fee can be one-off, as in Ireland, or renewable, ${ }^{7}$ and if set high enough, would encourage some retailers to abandon tobacco sales. ${ }^{6}$ An annual fee has the advantage that it is likely to trigger a re-evaluation of the decision to sell tobacco each year when the licence fee is due, potentially overcoming what appears to be retailer inertia encouraging continued sales, even if the profit from tobacco sales is perceived to be low. ${ }^{12}$ For example, one study of alcohol-licensed outlets in New South Wales (NSW) Australia (where there is no tobacco licence fee) found that more outlets rated tobacco sales as 'unimportant' (a rating of $1-3$ on a 7 point scale) than 'important' (a rating of 5-7), but most continue to sell. ${ }^{13}$

A licensing system for tobacco retailers therefore has many potential advantages, but to date, analyses of outlets that have stopped selling in the presence of a licensing system have been limited by being restricted to one legislative environment. ${ }^{9} 1012$ Such studies, while making important contributions to the small body of research examining why retailers stop selling, do not permit generalisations to other geographical areas and/or legislative environments. An exception is a recent companion piece to this article, which focuses on qualitative results from the same data collection exercise as this study-a comparison of tobacco retailers across three different licensing schemes. ${ }^{8}$ This study extends previous research by providing what we believe is the first large-scale comparison of tobacco retailing in the different tobacco retailer licensing schemes of three separate legislative environments (states) of Australia, while statistically adjusting for a number of potential confounders. It is hoped that the research will provide insight for policy-makers and tobacco control advocates into how tobacco retailers are likely to respond to different licensing systems. 


\section{METHOD}

\section{Sample}

The study reports on a telephone survey of tobacco retailers conducted in August 2018 across three Australian states with different tobacco licensing schemes; NSW, the most populous state in Australia, which requires retailers to register before they can sell tobacco, but does not charge an annual $\mathrm{fee}^{14}$; Victoria, the second most populous state, which has no registration or licensing system, and Western Australia (WA), which has had an annual fee-based licensing system since 2007 (currently \$A286, after six small increases since its inception). ${ }^{15}$ In all three states, retailers can lose the right to sell tobacco if they breach tobacco retailing legislation, though in practice, such a penalty appears to be very rare. ${ }^{16}$ As well as reflecting differences in licensing, the study was designed to reflect different types of tobacco retailers and different geographical and socioeconomic areas, with two important exceptions: first, outlets where the decision to sell is likely to be made at a head office level (ie, large supermarkets, chained 7-Eleven type stores and petrol (gas) stations, and any stores located within those petrol stations) were excluded. Second, alcohol licensed outlets were excluded in NSW, since they had previously been surveyed in a comparable study. ${ }^{13}$

\section{Participants and methodology}

The details of the study have been published elsewhere ${ }^{8}$ but key points are reproduced here for clarity. Potential participants were identified from lists of businesses obtained from data registry companies-illion (sic) for WA and Victoria, and Remington for NSW. Those lists included many businesses that would not typically sell tobacco (eg, wholesalers, importers and service businesses), so those types of businesses were excluded. Retailers remaining on the lists were called by a market research company, and a request made to speak with the manager or duty manager. Respondents were asked to describe their business type, and interviews with excluded outlet types were terminated. The remaining participants were asked if they sold tobacco, and if not, if they had ever sold. Those still selling were asked additional questions, including the importance of tobacco sales to their business on a 7-point scale ranging from 1 ('not at all important') to 7 ('very important'), the number of staff in the business and the distance to the nearest alternative cigarette retailer.

Since alcohol-licensed premises were excluded in NSW, and previous research has shown those outlets are most likely to stop selling, ${ }^{12}$ alcohol-licensed premises in other states were excluded from the analysis. (Including alcohol-licensed premises in the models would make comparisons of any unadjusted statistics (eg, means and proportions) across NSW and the other states difficult.) However, in order to test whether the exclusion of alcohol-licensed premises selectively biased the results, additional analyses were run including alcohol-licensed outlets in WA and Victoria. As expected, the proportion of outlets that had stopped selling was then higher (because alcohol-licensed outlets were more likely to stop selling), but otherwise the results were not materially different. (Additional analysis included in online supplementary tables $1-3)$.

\section{Statistical methods}

Logistic regression was used to examine associations between the dichotomous outcomes: (1) selling tobacco (vs not currently selling) and (2) stopping selling tobacco (vs not stopping) and the following outlet characteristics: retailer type (convenience store/general store, grocery stores, fruit and vegetable stores, newsagent/post office), accommodation), socioeconomic status (SES) of location (quintiles of socioeconomic advantage/disadvantage score) ${ }^{17}$ remoteness of location ${ }^{18}$ (five categories) and state (NSW, Victoria and WA), with OR as effect measure. Linear regression was used to examine associations between reported importance of selling tobacco scores (the seller's response on a scale from 1 to 7 of increasing importance) and the same outlet characteristics listed above, with differences in mean score as effect measure. Two additional variables asked only of current retailers-distance to the nearest alternative tobacco seller and number of staff employed at the outlet-were also included in the importance score analysis. Ordinal versions for those variables (where respondents had chosen an answer from a range) were coded with the left-hand cut-points (the minimum value from the selected range of values) and with 'don't know/can't say' responses coded as missing values. For each categorical independent variable (ie, the outlet characteristics), global tests of the null hypothesis of equal effects across categories were performed (with $\mathrm{p}$ values represented by the term ' $\mathrm{p}$ value' in tables) and we report ORs and 95\% CIs for individual categories using dummy coding. In addition, tests for linear trends were performed by inclusion of continuous/ordinal versions of independent variables where appropriate (with $\mathrm{p}$ values represented by the term ' $p$ trend' in tables). 'Don't know'/'can't say' responses were excluded as missing values in regression models but were included in the overall numbers and calculations of proportions. When testing for linear trends, interval scaled variables (number of staff, distance to nearest retailer) were coded ordinally and for variables that were not interval scaled (SES of location, remoteness of location), consecutive integers were used for coding. ${ }^{17}$ In post hoc supplementary analyses suggested by a reviewer, we refitted the regression models used to produce the main results (tables 1-3) using clustered robust standard errors with the cluster variable being the postcode of outlet location. ${ }^{18}$

\section{RESULTS}

\section{Response rate}

After exclusion of the businesses described above that are not typical tobacco retailers, 7271 potential tobacco retailers remained on the calling list, of whom 2744 (37.8\%) were not contactable. The remaining 4527 potential tobacco retailers were contacted and $3279(72.4 \%)$ agreed to participate in the survey. Tobacco sell status could not be determined for 24 retailers, which were therefore excluded. A further 327 were found to be a business type that is not a typical tobacco retailer (eg, wholesalers) and were also excluded. After also excluding alcohol-licensed outlets, the sample included 2140 retailers, including 646 current tobacco sellers (30.2\% of outlets), 249 former-sellers (11.6\%) and 1245 never-sellers (58.2\%). The sampling process is summarised in figure 1 .

\section{Analysis}

Results for the logistic regression examining associations between outlet characteristics and (1) selling tobacco (vs not currently selling) are shown in table 1, and for (2) stopping selling tobacco (vs not stopping) in table 3, both with OR as effect measure. Results for the linear regression examining associations between reported importance of selling tobacco scores and the same outlet characteristics, with the addition of the two additional variables asked only of current retailers-distance to the nearest alternative tobacco seller and number of staff employed at the outlet-are shown in table 3 (with differences in mean score as effect measure). Results using clustered robust 
Table 1 Predictors of selling tobacco

OR for current selling

(vs not current selling)

\begin{tabular}{|c|c|c|c|}
\hline Characteristic & Sellers $\mathrm{n} / \mathrm{N}(\%)$ & Unadjusted OR & Adjusted OR \\
\hline All retailers with known sell status & $646 / 2140(30.2)$ & & \\
\hline \multicolumn{4}{|l|}{ Retailer type } \\
\hline Convenience store/general store* & $180 / 262(68.7)$ & ref. & ref. \\
\hline Grocery stores, fruit and veg stores & $259 / 453(57.2)$ & 0.61 (0.44 to 0.84$)$ & $0.73(0.52$ to 1.02$)$ \\
\hline Newsagent/post office & $191 / 450(42.4)$ & 0.34 (0.24 to 0.46$)$ & 0.35 (0.25 to 0.49$)$ \\
\hline Accommodation & 16/975 (1.6) & 0.01 (0.00 to 0.01$)$ & 0.01 (0.00 to 0.01$)$ \\
\hline$P$ value & & $<0.001$ & $<0.001$ \\
\hline \multicolumn{4}{|l|}{ Socioeconomic status (SES) of location } \\
\hline 1-Lowest SES & $145 / 434(33.4)$ & ref. & ref. \\
\hline 2 & $163 / 585(27.9)$ & 0.77 (0.59 to 1.01$)$ & 0.80 (0.56 to 1.16$)$ \\
\hline 3 & $117 / 399(29.3)$ & 0.83 (0.62 to 1.11$)$ & 1.05 (0.70 to 1.58$)$ \\
\hline 4 & $95 / 330(28.8)$ & $0.81(0.59$ to 1.10$)$ & 1.19 (0.77 to 1.82$)$ \\
\hline 5-Highest SES & $126 / 392(32.1)$ & 0.94 (0.71 to 1.26$)$ & 1.10 (0.73 to 1.66$)$ \\
\hline$P$ value & & 0.310 & 0.402 \\
\hline$P$ trend & & 0.903 & 0.290 \\
\hline \multicolumn{4}{|l|}{ Remoteness } \\
\hline Major city & 250/795 (31.4) & ref. & ref. \\
\hline Inner regional area & $234 / 808(29.0)$ & $0.89(0.72$ to 1.10$)$ & 3.49 (2.52 to 4.85$)$ \\
\hline Outer regional area & $117 / 420(27.9)$ & 0.84 (0.65 to 1.09$)$ & 2.88 (1.93 to 4.29$)$ \\
\hline Remote area & $34 / 77(44.2)$ & 1.72 (1.07 to 2.77 ) & 5.73 (2.67 to 12.30$)$ \\
\hline Very remote & $11 / 40(27.5)$ & 0.83 (0.41 to 1.68$)$ & 5.71 (1.60 to 20.44) \\
\hline$P$ value & & 0.054 & $<0.001$ \\
\hline$P$ trend & & 0.940 & $<0.001$ \\
\hline \multicolumn{4}{|l|}{ State } \\
\hline WA (Annual licence fee) & $103 / 381(27.0)$ & ref. & ref. \\
\hline VIC (no fee or listing requirement) & $182 / 836(21.8)$ & 0.75 (0.57 to 0.99$)$ & 0.63 (0.42 to 0.94$)$ \\
\hline NSW (one-off listing requirement) & $361 / 923(39.1)$ & 1.73 (1.33 to 2.25$)$ & 0.86 (0.59 to 1.25$)$ \\
\hline$P$ value & & $<0.001$ & 0.030 \\
\hline
\end{tabular}

${ }^{*}$ Convenience store' included outlets that self-described as a lunch bar, deli, milk car and corner shop.

NSW, New South Wales; VIC, Victoria; WA, Western Australia.

standard errors were practically the same as the original results obtained using ordinary standard errors (online supplementary tables 4-6).

\section{What characterises outlets that sell tobacco, compared to those that do not?}

Table 1 shows the results of a logistic regression model examining differences in currently selling tobacco by outlets in the three states depending on outlet type, the SES of its postcode and its remoteness. There were significant differences in the likelihood of current selling depending on outlet type $(p<0.001)$, with newsagents/post offices and accommodation outlets significantly less likely to sell than convenience stores (the reference category). The likelihood of selling tended to be higher in more remote geographical areas (both $\mathrm{p}$ value and $\mathrm{p}$ trend $<0.001$ ). There was no difference in the probability of selling tobacco depending on the SES of the outlet's postcode $(p=0.402)$. Outlets in Victoria were significantly less likely to sell than in WA $(\mathrm{OR}=0.6395 \% \mathrm{CI}(0.42$ to 0.94$))$. On raw percentages, outlets in NSW were more likely to sell than those in WA $39.1 \%$ in NSW vs $27.0 \%$ in WA). However, after allowing for other factors in the model, the probability of selling by NSW retailers was not significantly different from those in WA (adjusted $\mathrm{OR}=0.8695 \% \mathrm{CI}(0.59$ to 1.25$))$.

\section{What characterises outlets that stop selling tobacco?}

Across the three states, $27.8 \%$ of outlets had stopped selling (see table 2), some within the previous year, and others more than 10 years previously. Convenience and grocery-type stores were less likely to stop selling than other outlets $(\mathrm{p}<0.001)$, and the likelihood of outlets stopping selling tended to decrease with increasing remoteness $(\mathrm{p}$ trend $=0.041$ ). NSW outlets were significantly less likely to stop selling than Victorian outlets $(p=0.003$ for test of equality of NSW and Victoria OR estimates). NSW outlets were also less likely to stop than WA, but the difference was not significant (Adjusted OR=0.74 95\% CI $(0.44$ to 1.27$))$.

\section{Which outlet types rate tobacco sales as most important?}

The perceived importance of tobacco sales was not able to be factored into the models predicting which outlets sell and which have stopped selling, because outlets not currently selling were not asked about the importance of tobacco sales. A separate model was therefore run to examine potential associations between self-reported importance of tobacco sales scores (ranging from 1 to 7, with higher scores indicating higher importance) for current tobacco retailers (see table 3). Consistent with the results for the outlets most likely to sell, and least likely to stop selling, convenience and grocery type stores rated tobacco sales 
Table 2 Predictors of stopping selling tobacco

\begin{tabular}{|c|c|c|c|}
\hline \multirow[b]{2}{*}{ Characteristic } & \multirow[b]{2}{*}{ Ex-sellers/ (current and ex-sellers) n/N (\%) } & \multicolumn{2}{|c|}{ OR for ex-selling (vs current selling) } \\
\hline & & Unadjusted OR & Adjusted $\mathrm{OR}^{\wedge}$ \\
\hline All retailers with known sell status & 249/895 (27.8) & & \\
\hline \multicolumn{4}{|l|}{ Retailer type } \\
\hline Convenience store/general store & $22 / 202(10.9)$ & ref. & ref. \\
\hline Grocery stores, fruit and veg stores & $26 / 285(9.1)$ & 0.82 (0.45 to 1.49$)$ & $0.73(0.40$ to 1.34$)$ \\
\hline Newsagent/post office & $159 / 350(45.4)$ & 6.81 (4.17 to 11.12$)$ & 6.35 (3.86 to 10.45$)$ \\
\hline Accommodation & $42 / 58(72.4)$ & $21.48(10.39$ to 44.40$)$ & 23.27 (10.95 to 49.42$)$ \\
\hline$P$ value & & $<0.001$ & $<0.001$ \\
\hline \multicolumn{4}{|l|}{ Socioeconomic status (SES) of location } \\
\hline 1-Lowest SES & $44 / 189(23.3)$ & ref. & ref. \\
\hline 2 & $70 / 233(30.0)$ & 1.42 (0.91 to 2.19 ) & 1.38 (0.83 to 2.29$)$ \\
\hline 3 & $41 / 158(25.9)$ & 1.15 (0.71 to 1.89$)$ & $0.96(0.55$ to 1.70$)$ \\
\hline 4 & $38 / 133(28.6)$ & 1.32 (0.80 to 2.18$)$ & 0.87 (0.47 to 1.64$)$ \\
\hline 5-Highest SES & $56 / 182(30.8)$ & 1.46 (0.92 to 2.32$)$ & 0.89 (0.49 to 1.62$)$ \\
\hline$P$ value & & 0.464 & 0.473 \\
\hline$P$ trend & & 0.215 & 0.365 \\
\hline \multicolumn{4}{|l|}{ Remoteness } \\
\hline Major city & $119 / 369(32.2)$ & ref. & ref. \\
\hline Inner regional area & $77 / 311(24.8)$ & 0.69 (0.49 to 0.97 ) & 0.52 (0.33 to 0.83 ) \\
\hline Outer regional area & $43 / 160(26.9)$ & 0.77 (0.51 to 1.17$)$ & $0.68(0.39$ to 1.18$)$ \\
\hline Remote area & $8 / 42(19.0)$ & $0.49(0.22$ to 1.10$)$ & $0.48(0.18$ to 1.27$)$ \\
\hline Very remote & $2 / 13(15.4)$ & 0.38 (0.08 to 1.75$)$ & $0.26(0.03$ to 1.96$)$ \\
\hline$P$ value & & 0.107 & 0.058 \\
\hline$P$ trend & & 0.019 & 0.041 \\
\hline \multicolumn{4}{|l|}{ State } \\
\hline WA (annual licence fee) & $37 / 140(26.4)$ & ref. & ref. \\
\hline VIC (no fee or listing requirement) & 96/278 (34.5) & 1.47 (0.94 to 2.30$)$ & 1.31 (0.75 to 2.28$)$ \\
\hline NSW (one-off listing requirement) & $116 / 477(24.3)$ & 0.89 (0.58 to 1.38$)$ & 0.74 (0.44 to 1.27$)$ \\
\hline$P$ value & & 0.010 & 0.013 \\
\hline
\end{tabular}

NSW, New South Wales; VIC, Victoria; WA, Western Australia.

as more important than newsagents/post offices (adjusted mean difference $=-1.7595 \% \mathrm{CI}(-2.14$ to to 1.36$))$ and accommodation outlets (adjusted mean difference $=-2.2595 \% \mathrm{CI}(-3.16$ to to 1.35$)$ ). Importance scores tended to be lower with increasing remoteness of the retailer $(\mathrm{p}$ trend $=0.028)$. No other retailer characteristics were associated with importance scores. Notable, however, is that while the mean importance score for all outlets was 4.8 (95\%CI (4.6 to 4.9), some outlet types (Newsagents/ post offices and accommodation outlets) rated tobacco sales below the midpoint of 4 on the 7-point importance scale.

\section{DISCUSSION}

The results show clear differences between outlet types in the likelihood of selling, stopping selling and the reported importance of tobacco sales for the outlets. Compared with other outlet types, convenience and grocery type stores were more likely to sell tobacco, less likely to stop selling and rated tobacco sales as more important. Precise comparisons are difficult because of the different descriptions used for different types of retailers, but those results are consistent with the higher market share of convenience stores, which captured $11.7 \%$ of Australian tobacco sales in 2017, and small grocers, with a market share of $5.9 \%$, compared with newsagents/tobacconist kiosks (with $0.9 \%$ ), and 'others', with $1.2 \%$ of sales. ${ }^{19}$ Those numbers need to be interpreted in terms of the numbers of each types of outlets, with one NSW study finding that convenience/ grocery stores comprised $22.6 \%$ of tobacco retailers in the state, and newsagents only $9.8 \% .^{12}$ So the results show a logical pattern of tobacco retailing-outlets from a category of retailer with lower market share are likely to rate tobacco sales as less important, be less likely to sell, and more likely to stop selling if they sell. However, the probability of selling, of stopping selling and reported importance of tobacco sales were also associated with the remoteness of the outlet. That may be explained by fewer supermarkets and tobacconists-which dominate tobacco market share in Australia, probably because they tend to have lower prices ${ }^{20}$-being located in remote areas. That absence of key competitors would then mean that other tobacco retailers in those areas have less competition, make more sales, and so even though they rate tobacco sales as less important on average, they are less likely to stop selling.

In WA, where tobacco retailers need to pay an annual licence fee to sell tobacco, a lower proportion of retailers sold tobacco compared with NSW (with no licence fee), and WA retailers were more likely to stop selling than those in NSW (though neither difference was significant). However, analysis of the adjusted odds of selling suggests that the WA licence fee does not explain the difference: Victoria, with no licensing system, had the lowest proportion of tobacco retailers across the three states, and the highest proportion of ex-sellers. In NSW, after allowing for other factors, retailers were (like Victoria) actually less likely to sell than in WA (adjusted OR=0.86). Among those who had ever sold, NSW retailers were less likely to stop selling tobacco than retailers in WA (consistent with some effect due 
Table 3 Mean importance and predictors of importance (on a scale from 1 ('not at all important') to 7 ('very important'))

\begin{tabular}{|c|c|c|c|c|}
\hline \multirow[b]{2}{*}{ Characteristic } & \multirow[b]{2}{*}{$\mathrm{N}(\%)$} & \multirow[b]{2}{*}{ Mean score (SD) } & \multicolumn{2}{|c|}{$\begin{array}{l}\text { Difference in mean importance scores } \\
(95 \% \mathrm{Cl})\end{array}$} \\
\hline & & & Unadjusted mean difference & Adjusted mean difference* \\
\hline All retailers with known sell status & $646(100.0)$ & $4.79(1.97)$ & & \\
\hline \multicolumn{5}{|l|}{ Retailer type } \\
\hline Convenience store/general store & $180(27.9)$ & $5.23(1.73)$ & ref. & ref. \\
\hline Grocery stores, fruit and veg stores & $259(40.1)$ & $5.56(1.55)$ & $0.33(0.00$ to 0.66$)$ & 0.37 (0.00 to 0.74$)$ \\
\hline$P$ value & & & $<0.001$ & $<0.001$ \\
\hline \multicolumn{5}{|l|}{ Socioeconomic status (SES) of location } \\
\hline 1-Lowest SES & $145(22.4)$ & $4.97(1.92)$ & ref. & ref. \\
\hline 2 & $163(25.2)$ & $4.89(2.05)$ & $-0.08(-0.52$ to 0.36$)$ & $-0.07(-0.47$ to 0.32$)$ \\
\hline 3 & $117(18.1)$ & $4.61(1.99)$ & $-0.37(-0.85$ to 0.12$)$ & $-0.35(-0.79$ to 0.08$)$ \\
\hline \multicolumn{5}{|l|}{ Remoteness } \\
\hline Major city & $250(38.7)$ & $4.85(1.95)$ & ref. & ref. \\
\hline Inner regional area & $234(36.2)$ & $4.63(2.03)$ & $-0.22(-0.57$ to 0.13$)$ & $-0.38(-0.77$ to 0.00$)$ \\
\hline Outer regional area & $117(18.1)$ & $5.04(1.89)$ & $0.19(-0.24$ to 0.63$)$ & $-0.18(-0.64$ to 0.28$)$ \\
\hline Remote area & $34(5.3)$ & $4.38(1.95)$ & $-0.47(-1.17$ to 0.24$)$ & $-1.06(-1.75$ to -0.37$)$ \\
\hline Very remote & $11(1.7)$ & $5.36(1.91)$ & $0.52(-0.67$ to 1.71$)$ & $-0.50(-1.61$ to 0.61$)$ \\
\hline$P$ value & & & 0.174 & 0.025 \\
\hline$P$ trend & & & 0.896 & 0.029 \\
\hline \multicolumn{5}{|l|}{ No of staff } \\
\hline 1 & $113(17.5)$ & $4.60(2.01)$ & ref. & ref. \\
\hline \multicolumn{5}{|l|}{ Distance to nearest tobacco retailer } \\
\hline Less than $100 \mathrm{~m}$ & $235(36.4)$ & $4.39(2.06)$ & ref. & ref. \\
\hline $100-199 m$ & $73(11.3)$ & $4.88(1.96)$ & $0.49(-0.02$ to 1.00$)$ & 0.48 (0.02 to 0.94$)$ \\
\hline $200-499 m$ & $80(12.4)$ & $4.75(1.96)$ & $0.36(-0.13$ to 0.86$)$ & $0.27(-0.18$ to 0.71$)$ \\
\hline $500-999 m$ & $65(10.1)$ & $4.92(1.91)$ & 0.54 (0.00 to 1.07$)$ & $0.06(-0.43$ to 0.55$)$ \\
\hline $1000 \mathrm{~m}(1 \mathrm{~km})$ or more & $190(29.4)$ & $5.18(1.79)$ & 0.80 (0.42 to 1.17 ) & $0.24(-0.14$ to 0.61$)$ \\
\hline Don't know/can't say & $3(0.5)$ & $7.00(0.00)$ & $\mathrm{n} / \mathrm{a}$ & $\mathrm{n} / \mathrm{a}$ \\
\hline$P$ value & & & 0.001 & 0.262 \\
\hline$P$ trend & & & $<0.001$ & 0.517 \\
\hline \multicolumn{5}{|l|}{ State } \\
\hline WA (annual licence fee) & $103(15.9)$ & $5.10(1.71)$ & ref. & ref. \\
\hline VIC (no fee or listing requirement) & $182(28.2)$ & $4.75(2.01)$ & $-0.35(-0.83$ to 0.13$)$ & $-0.38(-0.84$ to 0.09$)$ \\
\hline NSW (one-off listing requirement) & $361(55.9)$ & $4.72(2.01)$ & $-0.38(-0.81$ to 0.05$)$ & $-0.28(-0.71$ to 0.15$)$ \\
\hline$P$ value & & & 0.150 & 0.280 \\
\hline
\end{tabular}

n/a, not applicable; NSW, New South Wales; VIC, Victoria; WA, Western Australia.

to a licence fee), but the difference was not significant. There is certainly other evidence that an annual licence fee encourages some retailers to stop selling, ${ }^{89}$ so these unexpected results may be due to different levels of population density across the states: at $2529875 \mathrm{~km}^{2}$, WA is more than 11 times the land area size of Victoria (at $227416 \mathrm{~km}^{2}$ ), ${ }^{21}$ despite having only $39.8 \%$ of its population (2.62 million in WA vs 6.57 in Victoria). ${ }^{22}$ Consistent with that lower average population density, Victoria has no retailers in areas classified as very remote, and only seven retailers in areas classified as remote. NSW falls between the other two states in size (at 3.52 times Victoria's land area size, ${ }^{21}$ and the largest population, with 1.2 times Victoria's population size). ${ }^{22}$ Although the analysis allowed for remoteness of the location of the retailer, it is likely that the remoteness measure did not adequately capture those geographical differences across the states. For example, with Victoria having only seven retailers 
List of 38,128 businesses obtained

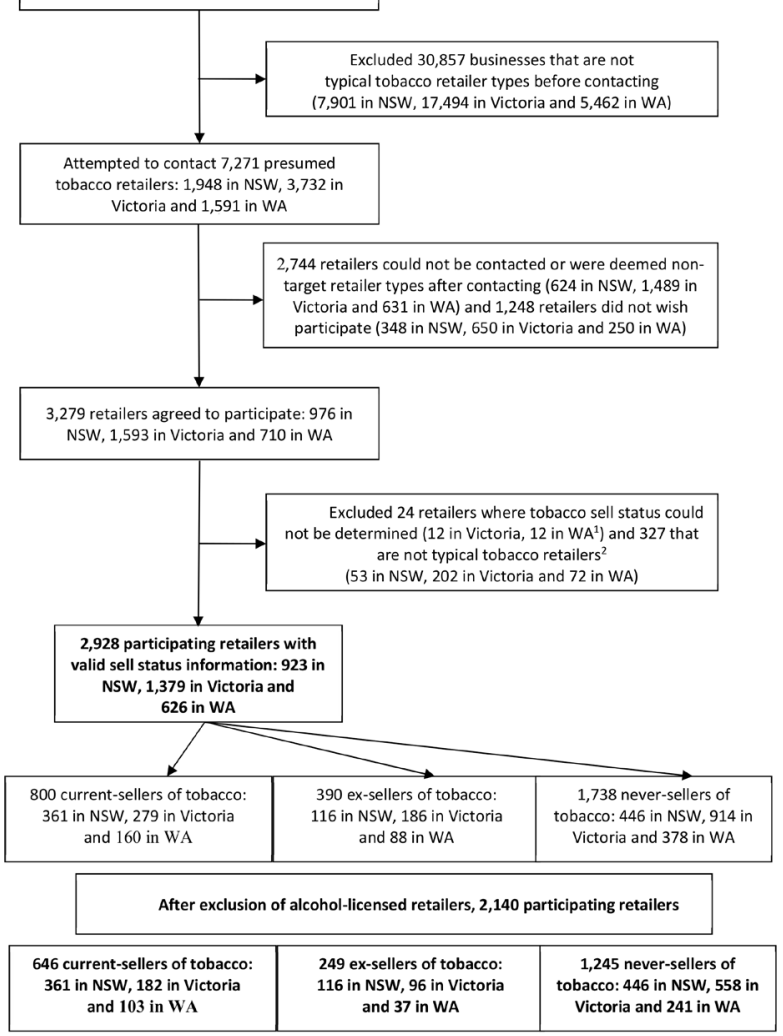

'Retailers that said they only sell in an attached bottle shop (an excluded category). These interviews were terminated after selling status through a bottle shop was established, so it is unknown whether they were 'exsellers' or 'never-sellers' in the main shop, because the 'ever seller' question was skipped for them.

2 'Non-typical retailers' included businesses such as wholesalers and importers.

Figure 1 Flow diagram showing outlet sampling process. NSW, New South Wale; WA, Western Australia.

in very remote areas and none in remote areas, and the second highest population spread across the smallest area of the three states, the state is likely to have a much higher percentage of the population living closer to an urban centre. Urban centres will almost certainly contain a supermarket and/or tobacconist which, on average, both sell tobacco at lower prices that other outlets. ${ }^{20}$ Proximity to lower-priced competitors will result in other retailers making less money from tobacco sales, so a higher percentage of those other outlets are likely to stop selling. In contrast in NSW, despite having a smaller land area than WA, like WA, there are remote and very remote regions where there are less likely to be supermarkets, and so in the absence of an annual licence fee, retailers are more likely to persist in selling tobacco even, in the face of low sales. So the results are consistent with a competitive disadvantage for small retailers in less remote areas where they are more likely to be exposed to lower-cost competitors, and thus more likely to stop selling. Conversely, in more remote areas, small retailers are less likely to face low-cost competition, and thus less likely to stop selling. That explanation is supported by market share figures which show an increase in the tobacco market share of supermarkets and tobacconists, and a decrease in all other store-based retailers. ${ }^{19}$ So when they can, Australian smokers appear to be increasingly buying from lower cost retailers, possibly driven by steep annual tax increases in the price of tobacco driving smokers to the (average) lower-priced outlets of supermarkets and tobacconists. ${ }^{23}$ That behaviour would then contribute to the higher exit from the market of small retailers in Victoria due to their greater exposure to those lower-cost retailers.

It is possible that the WA annual fee encourages some retailers to stop selling, consistent with the (non-significant) higher rate of stopping selling relative to NSW and with what they report themselves. ${ }^{8}$ However, with a licence fee of only \$A286, and likely low competition in remote and very remote areas, many continue to sell. So at that level of licence fee, factors such as population density and the resultant differences in lower-priced competitors appear to be more important in whether retailers continue to sell.

\section{CONCLUSION}

Rational businesses are likely to make supply and stocking decisions based on projected customer demand, so as the smoking rate continues to fall, more retailers are likely to stop selling tobacco if the profit becomes insufficient to justify sales. Some may stop selling due to concerns about the health problems associated with tobacco, ${ }^{24} 25$ although one systematic analysis of retailers who had stopped selling in NSW suggests that only a tiny percentage of retailers stop selling due to health concerns; in that study, only one retailer-who had just bought the business-decided to stop selling tobacco due to health concerns. ${ }^{12}$ Instead, many retailers appear to continue to sell, even if profits are low, due to what appears to be inertia, unless there is some change to the environment that triggers a re-evaluation of the advantages and disadvantages of selling. ${ }^{12}$ An annual fee-based licensing scheme can provide such a trigger. However, any deterrent to sell from an annual licence fee will also be tempered, or conversely increased, by the size of the fee and by geographical and market factors, such as actual and perceived competition and profitability. So the study suggests that the effect of licence fees on the number of tobacco retailers is likely to depend on multiple factors, and provides a warning that tobacco licensing cannot be expected to have an equivalent effect in areas with very different retail markets. Over time, as the number of smokers decreases, and the demand for, and profitability of, tobacco sales decreases, more retailers are likely to stop selling. An annual licensing fee is likely to hasten that decision, though these results suggests that to have a significant effect on the number of retailers, the fee would need to be higher than the one currently charged in WA.

\section{What this paper adds}

- There is increasing interest in the use of tobacco retailer licensing as a strategy to move towards a tobacco 'endgame', whether defined as no legal tobacco sales or smoking prevalence close to zero.

- However, there is only very limited evidence examining the importance of tobacco sales to retailers, why some stop selling, and how licensing could contribute to lower tobacco sales.

- In what we believe is the first large-scale study of tobacco retailing under very different licensing schemes, we show that an annual licence fee to sell tobacco of less than $\$ A 300$ may result in some retailers deciding to stop selling tobacco, but a licence fee at that level appears to be less important than other factors (eg, outlet type, perceived importance of tobacco sales and proximity to competitors) in the decision to sell. 
Contributors All authors contributed to the idea and to interpretation of the results. SB and SE led the analysis and wrote the first draft. All authors reviewed and approved the final version.

Funding This study was funded by Cancer Council Western Australia.

Competing interests No, there are no competing interests.

Patient consent for publication Not required.

Ethics approval Ethics approval was obtained from the Ethics Committee of Western Sydney University.

Provenance and peer review Not commissioned; externally peer reviewed.

Data availability statement Data are available on reasonable request.

Deidentified data are available on reasonable request by contacting the first author.

\section{ORCID iD}

Suzan Burton http://orcid.org/0000-0002-0305-6128

\section{REFERENCES}

1 Smith EA, Malone RE. An argument for phasing out sales of cigarettes. Tob Control 2020;29:703-8.

2 Malone RE. Imagining things otherwise: new endgame ideas for tobacco control. Tob Control 2010;19:349-50.

3 Thomson G, Wilson N, Blakely T, et al. Ending appreciable tobacco use in a nation: using a sinking lid on supply. Tob Control 2010;19:431-5.

4 Edwards R, Russell M, Thomson G, et al. Daring to DREAM: reactions to tobacco endgame ideas among policy-makers, media and public health practitioners. BMC Public Health 2011;11:580.

5 Ashe $\mathrm{M}$, Jernigan $\mathrm{D}$, Kline $\mathrm{R}$, et al. Land use planning and the control of alcohol, tobacco, firearms, and fast food restaurants. Am J Public Health 2003;93:1404-8.

6 Cohen JE, Anglin L. Outlet density: a new frontier for tobacco control. Addiction 2009;104:2-3.

7 Henriksen L. Comprehensive tobacco marketing restrictions: promotion, packaging, price and place. Tob Control 2012;21:147-53.

8 Watts C, Burton S, Phillips F, et al. Understanding why some Australian retailers have stopped selling tobacco, some might and some are unlikely. Tob Control 2020;29:e63-70.

9 Bowden JA, Dono J, John DL, et al. What happens when the price of a tobacco retailer licence increases? Tob Control 2014;23:178-80.
10 Vyas $\mathrm{P}$, Sturrock $\mathrm{H}$, Ling PM. Examining the role of a retail density ordinance in reducing concentration of tobacco retailers. Spat Spatiotemporal Epidemiol 2020;32:100307.

11 Fry R, Burton S, Williams K, et al. Retailer licensing and tobacco display compliance: are some retailers more likely to flout regulations? Tob Control 2017;26:181-7.

12 Feletto E, Burton S, Williams K, et al. Who stops selling? A systematic analysis of extobacco retailers. Tob Control 2016;26:164-8.

13 Burton S, Ludbrooke M, Williams K, et al. To sell or not to sell: cigarette sales in alcohol-licenced premises. Tob Control 2018;27:614-21.

14 Government of New South Wales. Public health (tobacco) act, 2008. Available: https:// www.legislation.nsw.gov.au/\#/view/act/2008/94 [Accessed 29 Aug 2019].

15 Department of Health Government of Western Australia. Tobacco sellers licensing: important information for tobacco product sellers, 2017. Available: https://ww2. health.wa.gov.au/Articles/S_T/Tobacco-sellers-licensing [Accessed Apr 2019].

16 Burton S, Walsberger SC, Williams K. Slapped with a fine or a slap on the wrist? enforcing tobacco licensing legislation. Tob Control 2018;27:e83-4.

17 Agresti A. Categorical data analysis. New York: John Wiley \& Sons, 2003.

18 Rogers W. Regression standard errors in clustered samples. Stata Technical Bulletin 1994;3.

19 Winstanley M, Freeman B, Bayly M, et al. Chapter 10 the tobacco industry in Australian Society, in tobacco in Australia: facts and issues. In: Scollo MM, Winstanley MH, eds. Melbourne: Cancer Council Victoria, 2019. https://www.tobaccoinaustralia. org.au/chapter-10-tobacco-industry/10-5-retailing-of-tobacco-products-in-australia

20 Burton S, Williams K, Fry R, et al. Marketing cigarettes when all else is unavailable: evidence of discounting in price-sensitive neighbourhoods. Tob Control 2014;23:e24-9.

21 Australian Bureau of Statistics. 1301.0 - Year Book 2007, 1.1 1.1 Area, coastline, tropical and temperate zones, 2007. Available: https://www.abs.gov.au/AUSSTATS/ abs@.nsf/productsbyCatalogue/DA1C7F83FF19B91DCA257235008133DC? opendocument [Accessed Nov 2019].

22 Australian Bureau of Statistics. 3101.0 - Australian Demographic Statistics, 2019. Available: https://www.abs.gov.au/ausstats/abs@.nsf/mediareleasesbyCatalogue/ CA1999BAEAA1A86ACA25765100098A47 [Accessed Nov 2019].

23 Egger S, Burton S, Ireland R, et al. Observed retail price of Australia's market-leading cigarette brand before and up to 3 years after the implementation of plain packaging. Tob Control 2019;28:e86-91.

24 McDaniel PA, Malone RE. Why California retailers stop selling tobacco products, and what their customers and employees think about it when they do: case studies. BMC Public Health 2011;11:848.

25 McDaniel PA, Malone RE. "People over profits": retailers who voluntarily ended tobacco sales. PLoS One 2014;9:e85751. 